\title{
Study on the Penetrating Property of Silane Hydrophobic Impregnating Agent in Concrete
}

\author{
Hongyao SUN \\ State Key Laboratory of Hydrology-Water Resources and \\ Hydraulic Engineering \\ Nanjing Hydraulic Research Institute \\ Nanjing, China \\ e-mail: rehaha@163.com \\ Xuechuan WANG \\ Nanjing Hydraulic Research Institute and Hehai University \\ Nanjing, China \\ e-mail: 835830127@qq.com
}

\author{
Zongyang YUAN \\ College of Mechanics and Material \\ Hehai University \\ Nanjing, China \\ e-mail: 457872878@qq.com
}

\begin{abstract}
That organosilicon hydrophobic impregnating agents such as silane are coated on the reinforced concrete surface is one of anticorrosion measures of reinforced concrete. The penetrating depth of organosilicon hydrophobic impregnating agents in concrete is an important parameter for the durability of reinforced concrete. There is no nondestructive measure method for measuring the penetrating depth of silane in concrete onsite by now, so it is expected to be obtained based on Darcy's law in this paper. The influence of different cement types and different water cement ratios on the penetrating depth of silane, the contact angle of silane, the concrete porosity and the concrete pore radius of the capillary were studied. The intrinsic permeability coefficients of concrete were researched by using Darcy's law. The surface contact angle on the concrete surface is almost the same with different cement types and different water cement ratios. The concrete total porosity and the pore radius are influenced by cement types and water cement ratios. The most probable pore radius has positive correlation to the penetrating depth of silane and the permeability coefficient of concrete. The permeability coefficient of concrete is not a constant and effected by cement types and water cement ratios, which is positively relation to the water cement ratio. The permeability coefficient of concrete cannot be used as a nondestructive measure method to calculate the penetrating depth of silane. The penetrating process of silane in concrete may not meet Darcy's law. The pore structure of concrete is complicated which is not a simple cylindrical pore. The pore structure of concrete and the pore structure of hardened cement paste are different. There are many factors affecting the pore structure of concrete. The water cement ratio and the aggregate diameter influence the porosity and permeability of concrete.
\end{abstract}

Keywords-organosilicon; water-repellent; impregnating agent; silane; concrete; anticorrosion; Darcy's law

\section{Gaoxia SUN}

State Key Laboratory of Hydrology-Water Resources and Hydraulic Engineering Nanjing Hydraulic Research Institute Nanjing, China

e-mail: gxsun@nhri.cn

\section{INTRODUCTION}

Coating with organosilicon water-repellent impregnating agents such as silane on concrete surface has been one of the anticorrosion measures for reinforced concrete. Because of the permeable performance of concrete, the organosilicon hydrophobic impregnating agents can permeate into concrete for a certain depth and form water repellent layer which can repel water and maintain the respiratory function of concrete without clogging the pores of concrete. The penetrating depth of organosilicon water-repellent impregnating agents in concrete is an important indicator of the durability of concrete. The status and prospect of test methods of silicone water repellent for protecting reinforced concrete was presented by Hongyao SUN [1]. There is not a nondestructive measurement method to measure the penetrating depth of organosilicon water-repellent impregnating agents by now.

Rui PEI [2] assessed the internal defects of reinforced concrete pool by calculating concrete penetrating coefficient with Darcy's law. Based on Darcy's law and electro kinetic effect which is produced by the pressed electrical double layer on the interface between the solid and the liquid in the concrete pores, Guang YANG [3] determined the similarity conditions and the main similarity coefficient of sample models by dimensional analysis. One can derive a relationship with material permeability from the knowledge of the properties of the porous network [4]. Upul ATTANAYAKA [5] reported that the impregnating process of organosilicon hydrophobic impregnating agents in concrete was agreed with the Darcy's law. Assuming the silane organosilicon water-repellent impregnating agent has steady flow within the porous network, Darcy's law for a small-impregnated volume is given thus: 


$$
d V_{\text {imp }}=\frac{k}{\eta} A \frac{\Delta P}{h(t)} d t
$$

Where: $V_{\text {imp }}$ is the impregnated volume within a time interval of $d t, k$ is the concrete intrinsic permeability coefficient that will be called "permeability coefficient" in this report, $\eta$ is the dynamic viscosity of silane, $A$ is the area normal to the surface, $\Delta P$ is the pressure gradient in the silane liquid, $h(\mathrm{t})$ is the penetrating depth at time t.

The $d V_{\text {imp }}$ is also expressed in terms of the porosity p and the penetrating depth $\mathrm{h}$ as:

$$
d V_{\mathrm{imp}}=p A d h
$$

And using the boundary condition $h(0)=0$, the penetrating depth $h$ can be expressed as:

$$
h^{2}=2 k t \Delta P /(\eta p)
$$

The $\Delta P$ is the differential capillary pressure, which can be expressed as:

$$
\Delta P=2 \gamma \operatorname{Cos} \theta / a
$$

Where: $\gamma$ is the surface tension, $\theta$ is the surface contact angle, $a$ is the pore radius of the cylindrical capillary.

So the Eq. (5) is obtained.

$$
h^{2}=\frac{4 k}{\eta} \frac{\gamma}{p} \frac{\operatorname{Cos} \theta}{a} t
$$

Because the properties of silane (the dynamic viscosity $\eta$, surface tension $\gamma$, surface contact angle $\theta$ is a constant value, the $K$ can be expressed as the equation $K=\eta /(\gamma t \operatorname{Cos} \theta)$ and the Eq. (6) is obtained.

$$
k=0.25 K h^{2} p a
$$

According to Eq. (6), if the properties of silane and specific concrete properties (the concrete porosity $p$ and the average pore radius a) are known and the permeability coefficient $k$ which is obtained from several concrete samples is not relationship with the concrete, the penetrating depth $h$ can be calculated based on Darcy's law.

The penetrating depth of silane in concrete is determined by splitting concrete or core drilling by now. But some reinforced concrete structures require integrity appearance, the methods of splitting concrete or core drilling are not allowed. If the permeability coefficient which can be determined by some other methods has no relationship with the concrete properties in Eq. (5), the impregnation depth shall be calculated according Eq. (5). Because the porosity and the pore radius of reinforced concrete are used to express concrete properties in Eq. (6), in theory, the permeability coefficient $k$ is not related to the performance of concrete. Therefore the relativity of the permeability coefficient $k$ with the concrete properties is studied in this paper.

\section{TEST MATERIALS}

Three kinds of cement were used, which were early strength Portland cement C-A (P.II 42.5R.), ordinary Portland cement C-B (P.O 42.5) and ordinary Portland cement C-C (P.O 42.5). Coarse aggregate and fine aggregate were $5 \sim 20 \mathrm{~mm}$ crushed stone and natural river sand with fineness modulus 2.8 respectively. Tap water was used as mixing water.

Isooctyl triethoxysilane (BS1701, 99\% silane) was selected as the organosilicon water-repellent impregnating agent. The formula of isooctyl triethoxysilane is $\mathrm{C}_{8} \mathrm{H}_{17}-\mathrm{Si}$ $\left(\mathrm{OC}_{2} \mathrm{H}_{5}\right)_{3}$. The group $\mathrm{C}_{8} \mathrm{H}_{17}$ - is a hydrophobic group and the group $\mathrm{C}_{2} \mathrm{H}_{5} \mathrm{O}$ - shall be hydrolysis to form chemical bond between silane and concrete when the silane is coated on the concrete surface.

\section{Test Methods}

\section{A. Molding Concrete}

Five sets of $100 \mathrm{~mm} * 100 \mathrm{~mm} * 100 \mathrm{~mm}$ test cubes with three specimens per set were cast and were removed from molds after $24 \mathrm{~h}$, then they were placed in the curing room $\left(20^{\circ} \mathrm{C}, \mathrm{RH} 90 \%\right)$ for $28 \mathrm{~d}$. The concrete mix compositions are listed in Table I.

TABLE I. The MiXing Composition OF SPECimens

\begin{tabular}{|c|c|c|c|c|c|c|}
\hline \multirow{2}{*}{$\begin{array}{c}\text { Sample } \\
\text { code }\end{array}$} & \multirow{2}{*}{$\begin{array}{c}\text { Cement } \\
\text { type }\end{array}$} & \multirow{2}{*}{$\boldsymbol{W} / \boldsymbol{C}$} & \multicolumn{4}{|c|}{ Weight of $\mathbf{1 m}^{3}$ concrete [kg] } \\
\cline { 4 - 7 } & & $\boldsymbol{C}$ & $\boldsymbol{S}$ & $\boldsymbol{C A}$ & $\boldsymbol{W}$ \\
\hline HL0.6 & C-A & 0.60 & 360 & 661 & 1078 & 216 \\
\hline JF0.6 & C-B & 0.60 & 360 & 661 & 1078 & 216 \\
\hline JN0.6 & C-C & 0.60 & 360 & 661 & 1078 & 216 \\
\hline JN0.55 & C-C & 0.55 & 360 & 668 & 1089 & 198 \\
\hline JN0.5 & C-C & 0.50 & 360 & 675 & 1100 & 180 \\
\hline
\end{tabular}

Note: W/C-water/cement, C-cement, S-sand, CA-coarse aggregate, W-water

\section{B. Coating Silane on the concrete Surface}

All specimens were removed from curing room after $28 \mathrm{~d}$ and then dried in oven at $60^{\circ} \mathrm{C}$ for $48 \mathrm{~h}$. They were taken out and polished with coarse sandpaper on surface to cleaning dust etc. and set aside for air drying. Then they were placed in the shrinkage room at $20^{\circ} \mathrm{C}$ and relative humidity $60 \%$ for $24 \mathrm{~h}$ and were taken out and coated with $300 \mathrm{~g} / \mathrm{m}^{2}$ silane on six surfaces of each concrete, while they should be coated for three times with $1 \mathrm{~h}$ coating interval time during the coating process. The coated specimens should be put in the shrinkage room at $20^{\circ} \mathrm{C}$ and relative humidity $60 \%$ for $14 \mathrm{~d}$.

\section{The Test of Physical Properties of Silane}

Before coating, physical properties of silane BS1701 must be tested at $20^{\circ} \mathrm{C}$ and relative humidity $60 \%$. Its dynamic viscosity $\eta$ was $1.88 \mathrm{~mm}^{2} / \mathrm{s}$ and surface tension $\gamma$ was $2.02 \times 10^{-2} \mathrm{~N} / \mathrm{m}$. The dynamic viscosity $\eta$ was tested by rotational viscometer (DV II+ Brookfield). The surface tension was tested by automatic surface tension meter (JK99C).

\section{The Test of the Surface Contact Angle}

The water repellent surface of reinforced concrete is formed after coated with silane. When the surface contact 
angle is more than $90^{\circ}$, the surface is a water repellent surface which the water cannot wet on. The surface contact angle was tested by U500X instrument.

\section{E. The Test of the Penetrating Depth of Silane}

The test specimens were split in half by a press machine and the $1 \%$ methylene blue solution was sprayed on the flash section of split specimen. The region without silane will show blue and the region including silane will show colorless which express the penetrating depth of silane. The average penetrating depth was obtained from 20 depths in different measure points of each specimen.

\section{F. The Test of the Concrete Porosity and the Average Pore Radius}

The concrete porosity $p$ and the average pore radius $r$ were measured by using mercury intrusion pressure instrument GT60. Some small concrete cube samples with side about several $\mathrm{mm}$ were obtained and then immersed in absolute ethanol for a short time before test. The samples were picked out from absolute ethanol and were dried in drying box at $90^{\circ} \mathrm{C}$ for more than $4 \mathrm{~h}$.

\section{RESUlTS AND DISCUSSION}

\section{A. Influence of Cement Type and W/C on the Surface Contact Angle of Specimens Coated with Silane}

The results of surface contact angle of specimens are listed in Table II.

TABLE II. Surface CONTACT ANGLE OF SPECIMENS

\begin{tabular}{|c|c|c|c|c|c|}
\hline SC & HL0.6 & JF0.6 & JN0.6 & JN0.55 & JN0.5 \\
\hline CT & C-A & C-B & C-C & C-C & C-C \\
\hline W/C & 0.60 & 0.60 & 0.60 & 0.55 & 0.50 \\
\hline $\boldsymbol{\theta}\left[{ }^{\circ}\right]$ & 119.9 & 120.5 & 120.4 & 120.7 & 120.3 \\
\hline \multicolumn{7}{r}{ Note: SC-sample code, CT-cement type, W/C-water/cement, $\theta$ - surface contact angle }
\end{tabular}

The results in Table II show that the contact angles of silane are almost the same with different cement types and water cement ratios. The cement type and the water cement ratio have no effect on the hydrophobic properties of silane. So the surface contact angle does not change with concrete properties and only relates to the type of organosilicon water-repellent impregnating agent.

\section{B. Influence of the Porosity and the Pore Radius of Concrete on the Permeability of Silane}

The results of the concrete porosity, the pore size and the penetrating depth of silane in concrete are listed in Table III.

The average pore radius $r$ is the arithmetic mean of all pore radii of a sample, and the most probable pore radius $a$ is the most distributed pore radii in all pores. The research data on the relationship between the concrete pore structure and the concrete permeability is less by now. Most are to investigate the relationship between the hardened cement paste pore structure and the cement paste permeability [6]. The relationship between the water cement ratio and the permeability coefficient of cement paste was studied by T. C. POWERS [7].
TABLE III. THE CONCRETE POROSITY PARAMETER OF SPECIMENS

\begin{tabular}{|l|c|c|c|c|c|}
\hline SC & HL0.6 & JF0.6 & JN0.6 & JN0.55 & JN0.5 \\
\hline CT & C-A & C-B & C-C & C-C & C-C \\
\hline $\boldsymbol{W / C}$ & 0.60 & 0.60 & 0.60 & 0.55 & 0.50 \\
\hline $\boldsymbol{h}[\mathbf{m m}]$ & 4.76 & 5.50 & 2.44 & 2.09 & 1.82 \\
\hline $\boldsymbol{p}[\boldsymbol{\%}]$ & 14.27 & 14.37 & 13.57 & 13.66 & 8.86 \\
\hline $\boldsymbol{r}[\mathbf{n m}]$ & 28.10 & 21.98 & 21.98 & 23.18 & 20.96 \\
\hline $\boldsymbol{a}[\mathbf{n m}]$ & 32.27 & 39.93 & 32.39 & 30.57 & 23.75 \\
\hline $\left.\boldsymbol{k} \mathbf{1}\left[\times \mathbf{1 0}^{-15} \mathbf{K}^{-1}\right] \mathbf{m}^{\mathbf{3}}\right]$ & 22.71 & 23.89 & 4.44 & 3.46 & 1.54 \\
\hline $\boldsymbol{k 2}\left[\times \mathbf{1 0}^{-15} \mathbf{K}\right]\left[\mathbf{m}^{\mathbf{3}}\right]$ & 26.08 & 43.39 & 6.54 & 4.56 & 1.74 \\
\hline
\end{tabular}

Note: SC-sample code, CT-cement type, W/C-water/cement, h- penetrating depth, p- porosity. The permeability coefficient $\mathrm{k} 1$ is calculated from average pore radius $\mathrm{r}$ as a and the permeability

\section{1) Effect of cement types on the concrete performance:}

According to Table III, the penetrating depth of HL0.6 is 2.13 times of JN0.6 and that of JF0.6 is 2.25 times of JN0.6. The PII cement which less than 5\% limestone or granulated blast furnace slag was added in cement clinker was used in specimens of HL0.6 set, so the concrete average pore radius $r$ and the penetrating depth of silane $h$ increased. Although the average pore radius $r$ of JF0.6 is the same as that of JN0.6, the result that the most probable radius $a$ and the porosity $p$ of concrete are larger than that of JN0.6 and HL0.6 causes that the penetrating depth of JF0.6 is larger than that of JN0.6 and HL0.6. It can be concluded that the concrete porosity, the pore radius and the penetrating depth of silane are influenced by the cement type. The correlation between the penetrating depth of silane and the concrete pore parameter with the same water cement ratio and different cement types is shown in Fig.1.

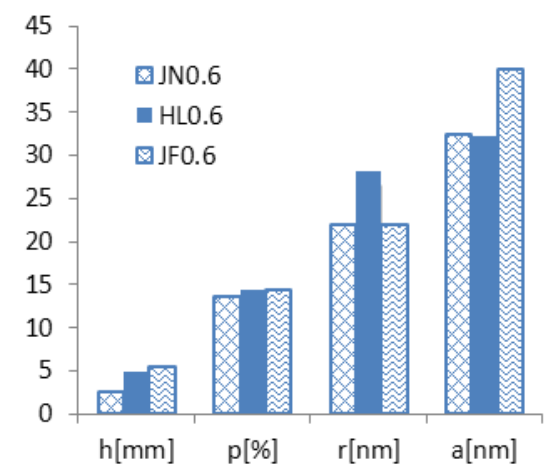

Figure 1. Correlation between the penetrating depth of silane and the concrete pore parameter

The results in Fig.1 show that the penetrating depth of silane $h$ has relationship to the concrete most probable radius $a$ and has little relationship to the concrete porosity $p$ and the average pore radius $r$ with the same water cement ratio and different cement types. The cement types has little influence on the concrete porosity $p$ with the same water cement ratio.

2) Effect of water cement ratio on the concrete properties:

The effects of water cement ratio on the concrete parameter and the penetrating depth of silane with the same 
cement type and different $W / C$ are shown in Table III and Fig.2.

The results inform that the water cement ratio $(W / C)$ has the positive relation to the penetrating depth $h$, the concrete porosity $p$ and the most probable radius $a$, but it has little relation to the average pore radius $r$. The smaller the water cement ratio of concrete specimens is, the denser the concrete is and the better the impermeability of concrete is. But the smaller the water cement ratio is, the smaller the penetrating depth of silane and the hydrophobic durability of silane are.

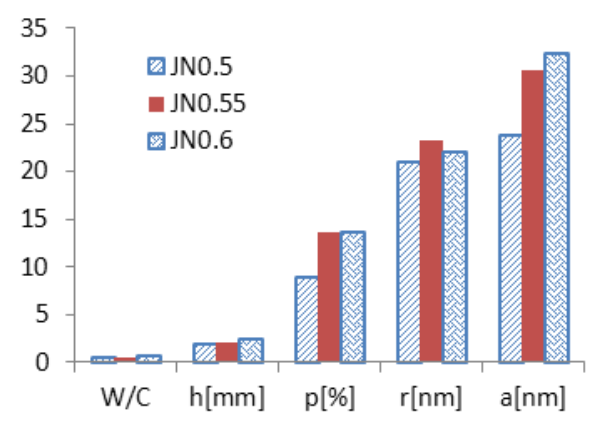

Figure 2. Influence of water cement ratio on concrete performance

\section{3) Effect of cement type on the permeability coefficient:}

According to Eq.(6), the concrete permeability coefficient $k$ should have positive relationship with the penetrating depth $h$, the porosity $p$ and the pore radius $a$. The calculating results of the permeability coefficient with the same water cement ratio and different cement types are showed in Fig. 3 and Table III.

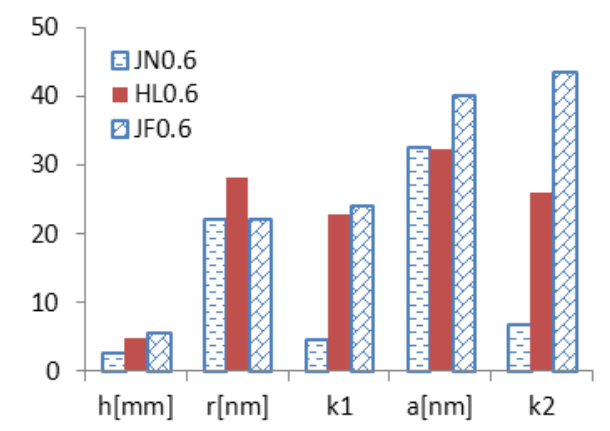

Figure 3. Effect of cement types on the permeability coefficient of concrete

The results show that the concrete permeability coefficient is not a constant with the same water cement ratio and different types of cement. The concrete permeability coefficient $k$ is consistent with the change trend of the penetrating depth $h$ of silane.

4) Effect of water cement ratio on the permeability coefficient of concrete:

The calculating results of the permeability coefficient with the same cement type and different water cement ratio are showed in Table III and Fig. 4. The results show that the water cement ratio affects the permeability coefficient of concrete and the value of concrete permeability coefficient is different. But the concrete permeability coefficient has positive correlation with the water cement ratio and the penetrating depth.

According to Fig.3 and Fig.4, although the concrete porosity and the pore radius are the representative of concrete pore parameters and are the indirect expression of concrete properties with cement type and water cement ratio, the concrete permeability coefficient is still subject to the influence of cement type and water cement ratio and not a fixed value. There may be two reasons to explain this phenomenon: 1) the concrete porosity and the pore radius cannot completely express the concrete performance; 2) the permeability of silane in concrete may not be consistent with Darcy's law.

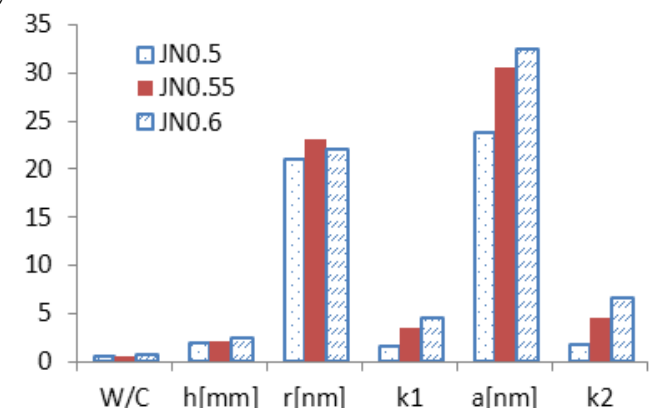

Figure 4. Effect of water cement ratio on the concrete permeability coefficient

Because the concrete permeability coefficient is affected by water cement ratio and cement type and is not a constant, the expectation of getting the penetrating depth of silane by using non-destructive measurement cannot be achieved.

\section{The Analysis of Concrete Permeability}

The C-S-H gel, calcium hydroxide, ettringite crystals and pores with a large pore size range are formed in the process of cement hydration. Therefore the gas or liquid can permeate into concrete. With the permeability of reinforced concrete, chloride ion and other harmful media can penetrate into the surface of reinforced bar to corrode steel bar, can be damage to the reinforced concrete and affect the durability of reinforced concrete structure. Some methods for reducing concrete permeability are used to protect reinforced concrete from corrosion, such as high performance concrete for improving concrete compactness, organic coatings for closing concrete pore and silicone hydrophobic impregnating agents for forming a hydrophobic layer on the concrete pore surface and etc..

1) Microstructure of Concrete Impregnated with Silane:

The effect of silane on the pore structure of concrete was observed by scanning electron microscope (SEM). The small concrete cubes with about $1 \mathrm{~cm}$ side in different parts of the concrete sample impregnated with silane are obtained and then loaded into the SEM instrument to scan. See Fig. 5(a) (d).

The microstructure of pore in the interior of the concrete is showed in Fig.5(a) and Fig.5(b). The pore structure is very complex and is not regular cylinder pore. There are through pores and closed pores, so the measured porosity is not equal to the real porosity which silane can penetrate into. 
The information in Fig.5(a) (d) informs that the compactness of concrete in different depth of concrete is not the same. The compactness within concrete is the smallest (Fig.5(a) \&. Fig.5(b)) and that on the surface of concrete is the biggest (Fig.5(d)). The sampling position affects the measurement value of the porosity and the pore radius and the value is scatter data. So the sampling position must be representative.

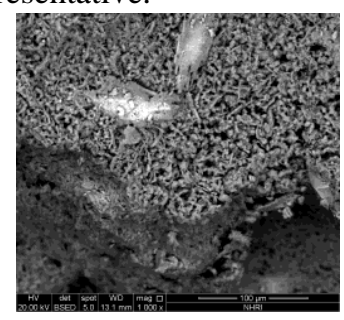

(a)

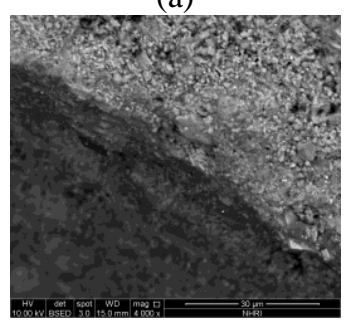

(c)

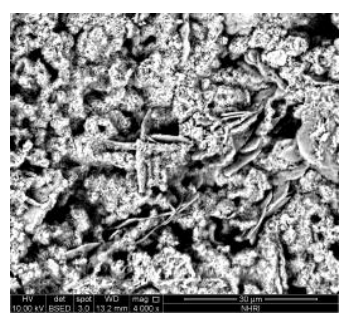

(b)

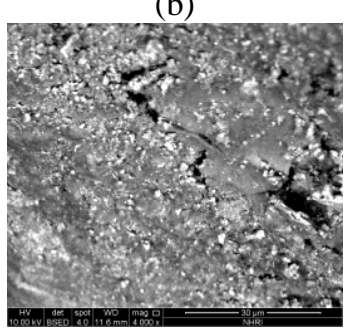

(d)
Figure 5. The microstructure of pore: (a) within concrete $(\times 1000)$; (b) within concrete $(\times 4000)$; (c) under the surface of concrete impregnated with silane ( $\times 4000)$; (d) the surface of concrete impregnated with silane $(\times 4000)$

2) Relationship between the pore structure and the permeability of concrete:

There are a lot of methods to determine the concrete pore [8]. The majority of the pore size distribution of the hardened cement paste is concentrated in the diameter of $3.6 \mathrm{~nm}-9 \mu \mathrm{m}$ which can be measured by high pressure measuring method such as MIP.

The relationship between permeability and capillary porosity of hardened cement paste was studied by T. C. POWERS [7] (Fig.6). The permeability increases with the increase of porosity. Especially when the porosity is greater than $25 \%$, the permeability coefficient increases rapidly with the increase of the porosity. While the porosity is lower than $20 \%$, the permeability coefficient is very small. And while the porosity is lower than $10 \%$, it can be considered almost impermeable.

In our research work, the pore structure of concrete is tested by the MIP method. The result that there is no direct correlation between the porosity and the permeability coefficient of concrete in Table III informs that there is difference between the concrete pore structure and the hardened cement paste pore structure. The permeability of concrete may depend mainly on the connectivity of the pore and the tortuous path for penetrating.

The reasons for the difference between concrete pore structure and hardened cement paste pore structure may be the forming method, curing condition, aggregate size, water cement ratio, cement content, cement type and so on.
The result in Fig.7 which is obtained based on Table III shows that the correlation between the permeability coefficient of concrete and water cement ratio is nearly linear correlation in the range of $0.5 \sim 0.6(W / C)$. While the water cement ratio increases, the concrete density decreases, the concrete porosity increases and the pore structure is easier to penetrate in.

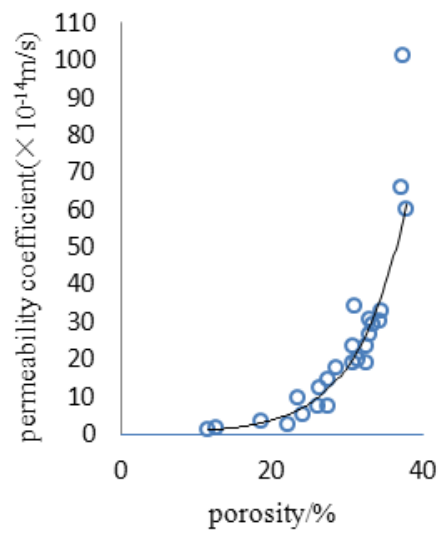

Figure 6. Relationship between permeability and capillary porosity of hardened cement paste

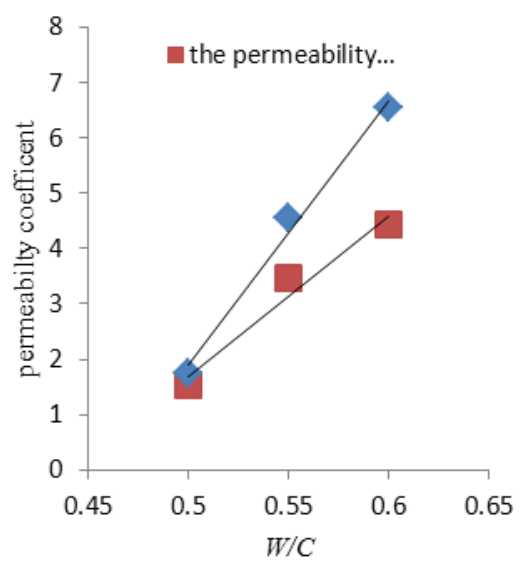

Figure 7. Relationship between water cement ratio and permeability coefficient of concrete

The relationship between water cement ratio and permeability coefficient of hardened cement paste with about cement hydration degree of $93 \%$ is showed in Fig.8 [7]. When the water cement ratio is below 0.4 , the permeability coefficient is so small and the density of hardened cement paste is so high that the hardened cement paste is almost impermeable. The variation trend of water cement ratio in range of $0.5-0.6(W / C)$ in Fig. 8 is similar to that of concrete in Fig.7. When the water cement ratio is above 0.5 , the permeability coefficient of concrete increases sharply with the increase of water cement ratio. The permeability coefficient is larger when the water cement ratio is above 0.7 .

According to the variation trend in Fig.6 and Fig.8, there is a positive correlation between water cement ratio and hardened cement paste porosity. But the result in Table III 
shows that the correlation between water cement ratio and the porosity of concrete is not obvious.

The effect of aggregate size on concrete properties has been studied, and the requests about the particle size of aggregate in concrete are embodied in a number of standards or specifications [9-10]. The diameter and gradation of aggregate have great influence on the pore structure of concrete. The influence of different water cement ratio and different maximum diameter of aggregate on the permeability of concrete was studied by R. K.DHIR [11] and showed in Fig.9.

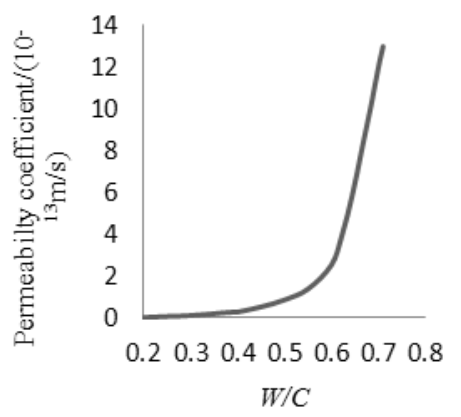

Figure 8. Relationship between water cement ratio and permeability coefficient of hardened cement paste

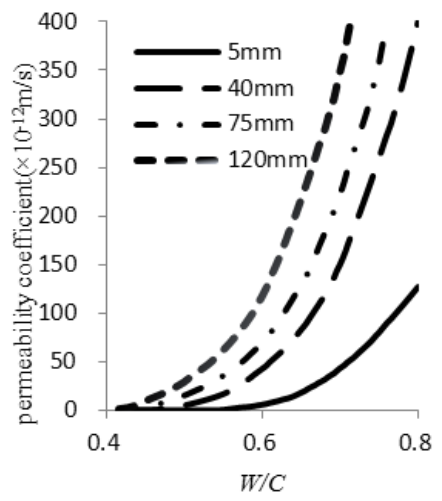

Figure 9. Effect of maximum aggregate diameter on the permeability of concrete with different water cement ratio

The results in Fig.9 show that the smaller the maximum diameter of aggregate, the more dense the concrete, the smaller the permeability coefficient of concrete and the greater the water cement ratio for the same permeability coefficient. When the diameter of coarse aggregate is smaller, the perimeter and the thickness of the transition zone between hardened cement paste and aggregate are so small that it is difficult to form a large defect and it is conducive to improve the interfacial strength and the impermeability of concrete. At the same time, the smaller the diameter of aggregate particle is, the smaller the defects of aggregate is.

\section{CONCLUSIONS}

The permeability of organosilicon water-repellent impregnating agent in concrete was studied. The test results show that the surface contact angle of silane on concrete surface has no relation with the concrete properties. The surface contact angles are almost the same with different cement types and different water cement ratios. The water cement ratio and cement type affect the concrete porosity and the pore radius. The most probable pore radius of concrete and the penetrating depth of silane have a positive correlation with the permeability coefficient. The concrete permeability coefficient is not a constant and can't be used to calculate the penetrating depth of silane as a non-destructive measurement method. The permeability of silane may not be consistent with Darcy's law.

The results in figures from SEM show that the pore structure of concrete is complicated and is not a regular cylindrical pore. There are closed pores and through pores in concrete. The analysis results of the relationship between pore structure and permeability inform that the pore structure of concrete and the pore structure of hardened cement paste are different. There are many factors affecting the pore structure of concrete, such as water cement ratio, aggregate diameter and so on. The larger the water cement ratio is, the larger the permeability coefficient of concrete is. The smaller the aggregate particle size is, the more compact the concrete is, and the smaller the concrete permeability coefficient is.

\section{ACKNOWLEDGMENT}

This work is financially supported by the National Natural Science Foundation of the P. R. China (51279110).

\section{REFERENCES}

[1] Hongyao SUN, Zongyang YUAN, Zheng YANG, Guoliang SHAN, Mingxia SHEN. "Status and Prospect of Test Methods of Silicone Water Repellent for Protecting Reinforced Concrete". 19th International Corrosion Congress, November 2-6, 2014, Jeju, Korea.

[2] Rui PEI. "The Assessment of Internal Defects of Reinforced Concrete with Dacy's Law”. LiaoNing Building Materials, 4, 2000:31-32.

[3] Guang YANG. "Discuss on Similarity Conditions of Model Test on Permeability of Concrete". Low Temperature Architecture Technology, 8, 2013:6-8.

[4] REYNES J., WOIGNIER T., and PHALIPPOU J.. "Permeability measurements in composite aerogels: application to nuclear waste storage". Journal of Non-Crystalline Solids, 285, 2001: 323-327.

[5] Upul ATTANAYAKA, Haluk AKTAN, Simon NG. "Criteria and Benefits of Penetrating Sealants for Concrete Bridge Decks". Report to Michigan Department of Transportation, December 2002.

[6] Shiyuan HUANG, Jiafen JIANG, Nanru YANG, Zhaotong ZHOU. "Modern Concrete Technology". Xi-an: Shaanxi Science and Technology Press, 1998.

[7] T. C. POWERS. "Physical Properties of Cement Paste". Proceedings of the Forth International Symposium on the Chemistry of Cement, Washington, 1960.

[8] Tiejun ZHAO. "Concrete permeability”. Beijing: Science Press, 2006.

[9] "Code for quality acceptance of concrete structure construction" (GB50204-2015). National Standard of the People's Republic of China. Beijing, 2015.

[10] "Code for durability design of concrete structures" (GB/T 504762008). National Standard of the People's Republic of China. Beijing, 2008

[11] R. K. DHIR. "Near surface characteristics of concrete: intrinsic permeability". Magazine of Concrete Research, 41(147), 1989:87-97. 